\title{
Genome-Wide Analysis of mRNAs and IncRNAs of Intramuscular Fat Related to Lipid Metabolism in Two Pig Breeds
}

\author{
Wanlong Huang Xiuxiu Zhang Ai Li Lingli Xie Xiangyang Miao \\ State Key Laboratory of Animal Nutrition, Institute of Animal Sciences, Chinese Academy of Agricultural \\ Sciences, Beijing, China
}

\section{Key Words}

IncRNA $・$ mRNA $・$ Intramuscular fat $\bullet$ Lipid metabolism $・$ Pig

\begin{abstract}
Background/Aims: Long non-coding RNAs (IncRNAs) can regulate adipogenesis and lipid accumulation. Intramuscular fat deposition appears to vary in different pig breeds, and the regulation mechanism has not yet been fully elucidated at molecular level. Moreover, little is known about the function and profile of IncRNAs in intramuscular fat deposition and metabolism in pig. The aim of this study was thus to explore the regulatory functions of IncRNAs in intramuscular fat deposition. Methods: In this study, Laiwu (LW) pig and Large White (LY) pig with significant difference in fat deposition were selected for use. RNA-seq technology and bioinformatics methods were used to comparatively analyze the gene expression profiles of intramuscular fat between LW and LY pigs to identify key mRNAs and IncRNAs associated with lipid metabolism and adipogenesis. Real-time fluorescence-based quantitative PCR was applied to verify the expression level of the differentially expressed mRNAs and IncRNAs. Results: A total of 513 mRNAs and 55 IncRNAs were differentially expressed between two pig breeds. By co-expression network construction as well as cis- and trans-regulated target gene analysis, 31 key IncRNAs were identified. Gene Ontology and KEGG pathway analyses revealed that differentially expressed genes and IncRNAs were mainly involved in the biological processes and pathways related to adipogenesis and lipid metabolism. Conclusion: XLOC_046142, XLOC_004398 and XLOC_015408 may target MAPKAPK2, NR1D2 and AKR1C4, respectively, and play critical regulatory roles in intramuscular adipogenesis and lipid accumulation in pig. XLOC_064871 and XLOC_011001 may play a role in lipid metabolism-related disease via regulating TRIB3 and BRCA1. This study provides a valuable resource for IncRNA study and improves our understanding of the biological roles of lipid metabolism- related genes and molecular mechanism of intramuscular fat metabolism and deposition.




\section{Cellular Physiology Cell Physiol Biochem 2018;50:2406-2422 \\ \begin{tabular}{ll|l} 
and Biochemistry & $\begin{array}{l}\text { DOI: } 10.1159 / 000495101 \\
\text { Published online: } 13 \text { November } 2018\end{array}$ & $\begin{array}{l}\text { ( } 2018 \text { The Author(s). Published by S. Karger AG, Basel } \\
\text { www.karger.com/cpb }\end{array}$ \\
\hline
\end{tabular} \\ Pigs}

\section{Introduction}

Intramuscular fat deposition is closely related to pork meat quality and appears to vary in different pig breeds. By selection of pigs with higher proportion of lean meat and higher growth rate, porcine backfat thickness is becoming thinner, but this has a negative effect on the intramuscular fat (IMF) levels in pig muscle [1]. In addition, human health problems caused by obesity are attracting more attention. It has been demonstrated that intramuscular adipocytes prefer to use glucose and obesity can lead to intramuscular lipid accumulation that is associated with several metabolic disorders including insulin resistance and type II diabetes [2,3]. Importantly, pig is anatomically and physiologically similar to human, thus it can be used as a good medical model for studying lipid metabolic disease [4-6]. Clarifying the molecular basis of fat deposition in pigs will deepen our understanding of diseases associated with fat metabolism.

Previous studies have shown that several genes might regulate intramuscular adipogenesis and lipid metabolism in pigs. They include stearoyl-CoA desaturase (SCD) [7-9], fatty acid synthase $(F A S N)[10,11]$, sterol regulatory element binding transcription factor 1 (SREBF1) [10], peroxisome proliferator-activated receptor $\gamma(P P A R \gamma)$ [12]. Some molecular events in the development of intramuscular fat have been recently revealed using longissimus dorsi muscle or adipocytes in pig [11, 13-15]. These studies indicate that adipocyte proliferation and differentiation is higher in subcutaneous fat than in intramuscular fat as well as in fat-type pig than in lean-type pig. Furthermore, the number and size of intramuscular adipocytes in fat-type pig are larger than those in lean-type pig. However, the regulatory mechanisms have not yet been fully elucidated. LncRNAs, nonprotein coding transcripts longer than 200 nucleotides, have important regulatory functions in adipogenesis and lipid metabolism. With the development of high throughput sequencing technology, RNA-seq has been widely applied in the identification and functional analysis of IncRNAs and mRNAs of adipose tissues in pig [7, 13, 16, 17], chicken [18], sheep [19, 20] and cattle [21]. Ramayo et al. [22] identified 270 and 186 lncRNAs in the liver tissues of female pigs with high and low intramuscular fatty acid contents, respectively. Zhou et al [14]. analyzed the methylation of IncRNAs and found the expression level of linc-sscg3623 varied with pig breeds and developmental stages, affecting fat synthesis. By identifying the lncRNA and mRNA expression profiles of preadipocytes at different stages in abdominal adipose tissue of Jinghai Yellow chicken, Zhang et al. found that the target genes of IncRNAs were significantly enriched in MAPK and PPAR signaling pathway associated with adipocyte differentiation [18]. These studies indicate that lncRNAs might determine fat deposition and fatty acid composition, and regulate adipogenic differentiation and lipid metabolism in livestock and poultry. However, there is limited research on the expression profiles and the functions of lncRNAs in intramuscular adipose tissue of pig breeds with significant differences in fat deposition.

Laiwu (LW) pig, a native breed prevalent in north China, is characterized by high quality meat with bright color, high water-holding capacity and especially high intramuscular fat content $(10.32 \%)$ [23]. On the contrary, Large White (LY) pigs, the most widely distributed lean-type pig breed, are faster-growing pigs with relatively low subcutaneous and intramuscular fat contents in comparison with Erhualian, Laiwu and Lulai Black pigs [15, 24]. Thus, LW and LY pigs provide good resources for studying intramuscular fat deposition, adipogenic differentiation and diseases associated with fat metabolism.

In this study, high-throughput RNA-seq was used to comparatively analyze the gene expression profiles of intramuscular adipose tissues in LW and LY pigs to identify key IncRNAs and genes associated with adipogenesis and lipid metabolism. Furthermore, by Gene Ontology (GO), Kyoto Encyclopedia of Genes and Genomes (KEGG) pathway, and Coexpression analyses, we investigated the molecular mechanism of differentially expressed lncRNAs and genes regulating fat deposition. The results can provide useful information for studying fat deposition regulated by lncRNAs in porcine intramuscular adipose tissue. 


\section{Cellular Physiology Cell Physiol Biochem 2018;50:2406-2422 \begin{tabular}{l|l|l} 
and Biochemistry Published online: 13 November 2018 & $\begin{array}{l}\text { (c) } 2018 \text { The Author(s). Published by S. Karger AG, Basel } \\
\text { www.karger.com/cpb }\end{array}$ \\
\hline
\end{tabular}

\section{Materials and Methods}

\section{Ethics statement}

All the procedures involving animals were approved by the animal care and use committee at the Institute of Animal Sciences, Chinese Academy of Agricultural Sciences, where the experiment was conducted. All the experiments were performed in accordance with the relevant guidelines and regulations set by the Ministry of Agriculture of the People's Republic of China.

\section{Animals and samples preparation}

The experimental animals used here included 3 female LW pigs and 3 female LY pigs. All pigs were raised in Daqian Farming Co. Ltd. of Laiwu (Laiwu city, Shangdong Province, China) and fed a diet formulated to meet current nutritional requirements (National Research Council, NRC, 1998) [25] when these pigs were weaned at about 1 month of age with an average weight of about $5.5 \mathrm{~kg}$. At slaughter age (180-day-old), the mean body weights of LW pigs and LY pigs were $40 \mathrm{~kg}$ and $108 \mathrm{~kg}$, respectively. There are some differences in growth and carcass quality among different pig breeds. As a result, different pig breeds possess a different slaughter weight at slaughter age. On the other hand, the metabolic reaction is at equilibrium in the slaughter period. Therefore, we sampled at slaughter age, which is more representative. The intramuscular fat tissues were obtained from the longissimus dorsi muscle immediately after the pigs were slaughtered and then deeply frozen at $-80^{\circ} \mathrm{C}$ until use.

Total RNA isolations and Illumina sequencing

Total RNAs were extracted from the intramuscular adipose tissues not separated from longissimus dorsi samples of individual LW and LY pigs using mirVanaTM RNA Isolation Kits (\#AM1561, Ambion, USA) according to the manufacturer's instructions. The quality and quantity of the RNA samples were analyzed by Bioanalyzer 2100 system using an RNA 6000 Nano kit (Agilent technologies, Inc., Santa Clara, USA). The isolated RNAs were treated with RNase-free DNase I (Ambion, Inc., Austin, USA) to avoid any potential genomic DNA contamination. Then, approximately $2 \mu \mathrm{g}$ of total RNAs from each sample was used for the construction of cDNA libraries (including LW1, LW2 and LW3; LY1, LY2 and LY3) according to Illumina ${ }^{\circledR}$ TruSeq ${ }^{\mathrm{TM}}$ RNA Sample Preparation protocol. Agilent DNA 1000 kit on a Bioanalyzer 2100 (Agilent technologies, Inc., Santa Clara, USA) was applied to check the size and purity of each cDNA library. These libraries were sequenced on the platform of Illumina HiSeq 2500 with 100 paired-end sequencing (Illumina, CA, USA).

\section{Reference genome mapping and transcriptome assembly}

After removing adaptor contaminants and low-quality reads from the raw reads using Fastx_toolkit software (v0.0.14), the remaining sequences were used for further analysis. Clean reads of each sample were then aligned to reference genome Sscrofa10.2 (ftp://ftp.ensembl.org/pub/release-87/fasta/sus_ scrofa/dna/) with Tophat2 software (v2.0.12) [26, 27]. The resulting alignment data from Tophat2 were then fed to Cufflinks (v2.1.1) [28, 29] for transcriptome assembly and reconstruction to obtain a nonredundant unified set of transcripts. Subsequently, these transcripts were aligned to reference annotation files Sscrofa10.2.87.chr.gtf (ftp://ftp.ensembl.org/pub/release-87/gtf/sus_scrofa) for identification of their types and positions. Transcript abundances were evaluated in Fragments Per Kilobase of exon per Million fragments mapped (FPKM), which eliminated the influence of sequencing depth, gene length and sample difference on gene expression level.

\section{SNP detection}

SNP detection was conducted with the SAMtools pileup program [30] to find variations in the SAM files and then VarScan program [31] to identify and filter variants based on read counts, base quality and allele frequency. 


\section{Cellular Physiology Cell Physiol Biochem 2018;50:2406-2422 \begin{tabular}{l|l|l} 
and Biochemistry Published online: 13 November 2018 & $\begin{array}{l}\text { (c) } 2018 \text { The Author(s). Published by S. Karger AG, Basel } \\
\text { www.karger.com/cpb }\end{array}$
\end{tabular} \\ Huang et al.: mRNAs and IncRNAs of Intramuscular Fat Related to Lipid Metabolism in \\ Pigs}

\section{Identification of IncRNAs}

Potential IncRNA candidates were identified as follows. First, transcripts blasted to known mRNAs and belonging to other types of non-coding RNAs (including pseudogenes, pre-microRNA, tRNA, etc.) were removed. Then, transcripts with single exon and length less than $200 \mathrm{bp}$ were excluded. PLEK [32], CNCI [33], CPC [34] and Pfam [35] were applied to assess the protein-coding potential of the above-obtained transcripts and the intersection of the results from these software tools was taken as the final result. In order to identify known IncRNAs, BLASTN tool was used to align IncRNA candidates to ALDB (A DomesticAnimal Long Noncoding RNA Database) [36], a database with a focus on the domestic-animal IncRNAs, with the settings of identity $=100 \%$, mismatch $=0$, E-value $<1 \mathrm{e}-10$ and gap_opening $=0$.

\section{Analysis of differentially expressed genes}

Three biological replicates were set in the experiment. Differentially expressed lncRNAs and mRNAs were identified based on negative binomial distribution using R package DESeq2 [37]. Multiple hypothesis testing correction of $\mathrm{P}$ value was performed with Benjamini-Hochberg algorithm. If $\mid \log 2$ FoldChange $\mid \geq 1$ (LW vs LY) and padj (adjusted P value) $\leq 0.05$, the genes and IncRNAs were considered to be differentially expressed.

\section{Functional enrichment analysis of differentially expressed genes}

GO (http://www.geneontology.org/) is the international standard classification of gene functions. It classifies gene functions along three aspects including molecular function, biological process and cellular component. KEGG (http://www.genome.jp/kegg) database [38] is a main public database for metabolic analysis and regulatory network research. To explore the main biological functions of differentially expressed genes, GO and KEGG signaling pathway enrichment analyses of mRNAs were performed using ClueGO [39] plugin of Cytoscape, based on hypergeometric distribution. Benjamini-Hochberg algorithm was used for $P$ value correction. GO terms and pathways with $Q$ value (corrected P value) $\leq 0.05$ were considered as significantly enriched.

\section{Target gene prediction of differentially expressed IncRNAs and functional analysis}

LncRNAs can cis-regulate neighboring target genes and trans-regulate distant target genes. Besides, genes with the same expression pattern might exhibit high correlation between biological functions. On the basis of above theories, the target genes of IncRNAs and key IncRNAs were identified as follows. For expression pattern analysis, Pearson correlation coefficient (PCC) was calculated for the expression values of each IncRNA and each mRNA, and co-expressed IncRNA-mRNA was selected with $|\mathrm{PCC}|>0.8$ and $\mathrm{P}$ value $<$ 0.05 . The genes transcribed within a 300-kb window upstream or downstream of IncRNAs were considered as cis target genes if the $|\mathrm{PCC}|$ of IncRNA-mRNA $>0.9$. RNAplex [40] was applied to select trans-acting target genes according to the interaction between IncRNA and mRNA sequences with $|\mathrm{PCC}|>0.9$ and Energy value $<-20[41,42]$. GO annotation and KEGG pathway enrichment analysis were performed for these target genes to investigate the biological processes and signaling pathways that lncRNAs were mainly involved in and the functions of IncRNAs.

\section{Construction of co-expression network between IncRNAs and mRNAs related to adipogenesis}

According to the results of correlation coefficient analysis as well as GO and KEGG analyses, the differentially expressed genes related to lipid metabolism, fat-associated diseases and adipocyte differentiation were selected ( $|\mathrm{PCCs}|>0.9$ ) for co-expression construction to identify the key IncRNAs regulating fat deposition. Combined with cis- and trans-regulation analysis of IncRNAs, the total key IncRNAs were identified to serve as a basis for further research on IncRNA functions. GO annotation and KEGG enrichment analysis of the target genes of each IncRNA were performed, and the IncRNA-mRNA-signaling pathway network was constructed using Cytoscape [43] to further explore the functions of each key lncRNA.

\section{qRT-PCR verification}

qRT-PCR was performed to verify the expression level of genes. Eleven differentially expressed genes (five lncRNAs and six mRNAs) were randomly selected. Three biological replicates were set for each gene. GeneAmp® PCR System 9700 (Applied Biosystems, USA) was used to synthesize cDNA templates via reverse transcription. Approximately $0.5 \mu \mathrm{g}$ of each RNA sample was used. QuantiFast ${ }^{\circledR}$ SYBR $\circledast$ Green PCR 


\section{Cellular Physiology Cell Physiol Biochem 2018;50:2406-2422 \\ \begin{tabular}{l|l|l} 
and Biochemistry Published online: 13 November 2018 & $\begin{array}{l}\text { (c) } 2018 \text { The Author(s). Published by S. Karger AG, Basel } \\
\text { www.karger.com/cpb }\end{array}$ \\
\hline
\end{tabular} \\ Huang et al.: mRNAs and IncRNAs of Intramuscular Fat Related to Lipid Metabolism in \\ Pigs}

Kit (Qiagen, Germany) and LightCycler@ 480 II Real-time PCR Instrument (Roche, Swiss) were used for qRT-PCR analysis. The reaction system consisted of $1 \mu \mathrm{L}$ of cDNA, $5 \mu \mathrm{L}$ of $2 \times$ QuantiFast $\AA$ SYBR $\AA$ Green PCR Premix (Qiagen, Germany), $0.2 \mu \mathrm{L}$ of forward primer, $0.2 \mu \mathrm{L}$ of reverse primer and $3.6 \mu \mathrm{L}$ of nucleasefree water. Reaction conditions were as follows: pre-denaturation at $95^{\circ} \mathrm{C}$ for $5 \mathrm{~min}$, followed by 40 cycles; denaturation at $95^{\circ} \mathrm{C}$ for $10 \mathrm{~s}$; renaturation at $60^{\circ} \mathrm{C}$ and extension for $30 \mathrm{~s}$. Pig $\beta$-actin (ACTB) gene was used as the internal control [44] and $2^{-\Delta \Delta c_{t}}$ method was used to calculate the relative expression levels of genes between samples.

Statistical analysis

All the data were presented as "means \pm SDs". When comparisons were made, a Student's t-test was performed and $\mathrm{P}<0.05$ was considered statistically significant.

\section{Results}

\section{Total RNA sequencing and mapping}

By RNA-seq, approximately $11 \mathrm{~Gb}$ of sequence data per library were obtained. After pre-processing and low-quality trimming of the sequence data, about 88.9-91.6 million clean reads were obtained for each sample. Approximately $73.5 \%-76.3 \%$ of the reads were successfully aligned to the scrofa reference genome, and more than $60 \%$ reads were uniquely mapped (Table 1). A total of 92, 172 transcripts were obtained (FPKM $\geq 0.01$ ), including 22, 712 known transcripts according to transcriptome assembly and reconstruction.

\section{Polymorphism detection}

A total of 1, 048, 575 variations due to SNPs in each unigene were identified. Putative SNPs detected in uniquely mapped reference sequence were plotted along pig chromosomes. We found that several SNPs were mapped to some lipid metabolism-related genes, including PER1 Period Circadian Clock 1 (PER1), Microtubule Associated Protein Tau (MAPT) and Eukaryotic Translation Initiation Factor 4E Binding Protein 1 (EIF4EBP1).

\section{Identification and characterization of IncRNAs}

A total of 1484 long intergenic noncoding RNAs (lincRNAs), 149 anti-sense lncRNAs, 136 sense lncRNAs and 97 intronic IncRNAs were identified in the six libraries (Fig. 1A). LincRNA was the most common type of IncRNA and its proportion was also the largest, which were consistent with current research (Fig. 1A). Among all the lncRNAs, 754 (about 40.41\%) were mapped to ALDB database. The majority of lncRNAs had two exons (up to 31 exons, an average of 2.99 exons), which were significantly less than that of protein-coding genes (up to 118 exons, an average of 9.64 exons) (Fig. 1B). In addition, the amount of exons in IncRNAs in intramuscular adipose tissue was consistent with that in thyroid [45] and testicular tissue [46] of pig. Overall, the distribution of IncRNAs and mRNAs lengths were consistent, and the proportion of relatively long mRNA transcripts was higher than that of IncRNAs (Fig. 1C). The average lengths of lncRNAs and mRNAs were 2317 and $2229 \mathrm{nt}$, respectively. Violin plot of

Table 1. Summary of raw reads after quality control and mapping to the reference genome

\begin{tabular}{lccccccc}
\hline Sample & $\begin{array}{c}\text { Raw } \\
\text { reads }\end{array}$ & $\begin{array}{c}\text { Clean } \\
\text { reads }\end{array}$ & $\begin{array}{c}\text { Valid } \\
\text { ratio(\%) }\end{array}$ & Q30(\%) & $\begin{array}{c}\text { GC } \\
\text { content(\%) }\end{array}$ & $\begin{array}{c}\text { Total mapped } \\
\text { reads }\end{array}$ & $\begin{array}{c}\text { Uniquely mapped } \\
\text { reads }\end{array}$ \\
\hline LY1 & 94261614 & 90180702 & $95.61 \%$ & $94.48 \%$ & $51.00 \%$ & $68721069(76.2 \%)$ & $57152404(63.38 \%)$ \\
LY2 & 94457608 & 90392480 & $95.63 \%$ & $94.48 \%$ & $49.50 \%$ & $90392480(76.31 \%)$ & $57838075(63.99 \%)$ \\
LY3 & 94739548 & 91093142 & $96.09 \%$ & $94.74 \%$ & $53.50 \%$ & $69180297(75.94 \%)$ & $54565312(59.9 \%)$ \\
LW1 & 92489412 & 88890352 & $96.05 \%$ & $95.30 \%$ & $50.00 \%$ & $65333853(73.5 \%)$ & $53927221(60.67 \%)$ \\
LW2 & 92272792 & 89083366 & $96.48 \%$ & $95.60 \%$ & $51.00 \%$ & $65710645(73.76 \%)$ & $55289541(62.06 \%)$ \\
LW3 & 95371148 & 91659768 & $96.04 \%$ & $95.26 \%$ & $49.00 \%$ & $67630486(73.78 \%)$ & $56360402(61.49 \%)$ \\
\hline
\end{tabular}




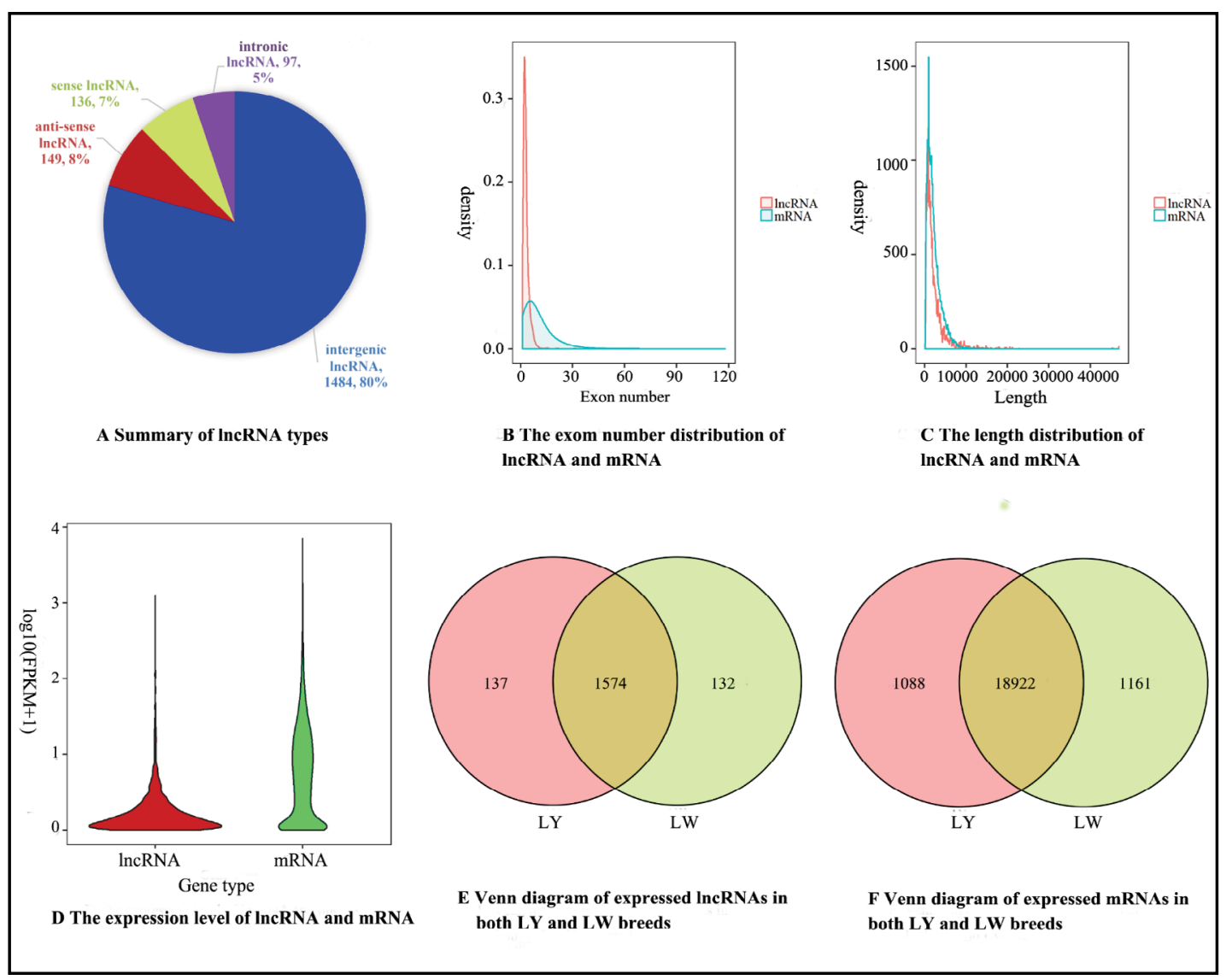

Fig. 1. Summary of lncRNA characteristics and gene expression. A. Summary of lncRNA types. B. The exon number distribution of lncRNAs and mRNAs. C. The length distribution of lncRNAs and mRNAs. D. The expression levels of IncRNAs and mRNAs. E. Venn diagram of expressed lncRNAs in both LY and LW pigs. F. Veen diagram of expressed mRNAs in both LY and LW pigs. All figures were drawn using R language.

FPKM values for the transcripts indicated that the expression level of mRNAs was relatively higher than that of IncRNAs (Fig. 1D), which was consistent with the research results on pig [46], mouse [47] and human [48].

\section{Differential gene expression analysis}

The Venn Diagram of the expressed lncRNAs and mRNAs showed that a total of 132 lncRNAs and 1161 mRNAs were expressed specifically in the intramuscular adipose tissue of LW pig, and 137 IncRNAs and 1088 mRNAs were expressed specifically in that of LY pig (Fig. 1E and F). A total of 55 differentially expressed lncRNAs (33 up-regulation and 22 down-regulation) (Table S1 - for all supplemental material see www.karger. com/10.1159/000495101/) and 715 differentially expressed mRNAs (371 up-regulation and 344 down-regulation), including 513 known mRNAs (Table S2), were identified.

\section{GO annotation of differentially expressed genes}

GO enrichment analysis results showed that 210 genes were enriched in the biological process category, 144 genes were enriched in the molecular function category, and 62 genes were enriched in the cellular component category. Importantly, many of the significantly enriched GO terms were closely associated with lipid metabolism and adipogenesis (Table S3). As shown in Fig. 2, In the biological process category, many genes $(\geq 15)$ were enriched in "lipid biosynthetic process", "lipid metabolic process", "cellular lipid metabolic process", "response to lipid", "MAPK cascade", "positive regulation of MAPK cascade" and "regulation 
Huang et al.: mRNAs and IncRNAs of Intramuscular Fat Related to Lipid Metabolism in Pigs

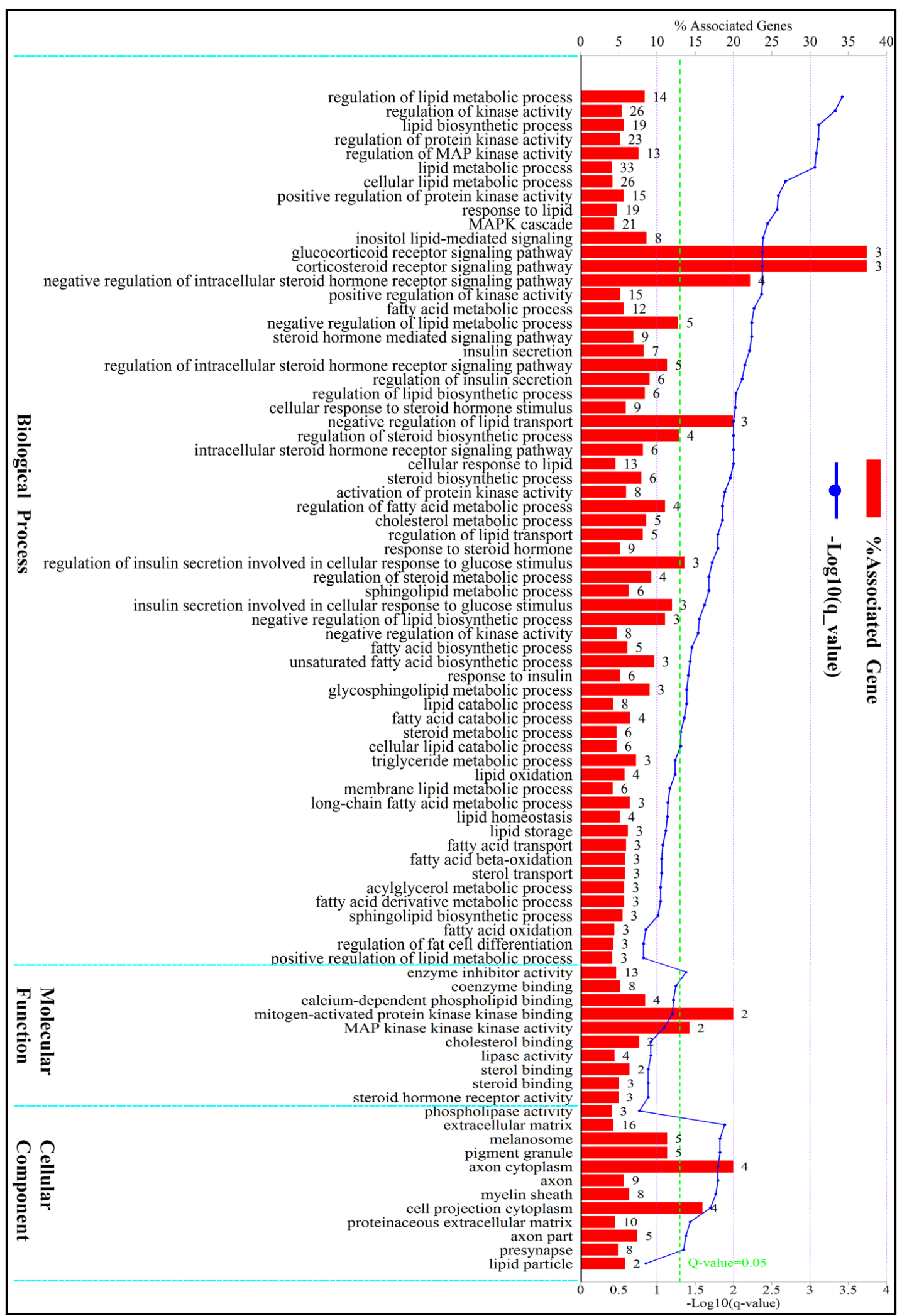

Fig. 2. GO analysis of differentially expressed genes. The figure is composed of three parts: biological processes, molecular functions, and cellular components. The significance level of enrichment was set at corrected $P$ value $(Q$ value $)<0.05$. The figure was drawn using $\mathrm{R}$ language. 


\section{Cellular Physiology Cell Physiol Biochem 2018;50:2406-2422

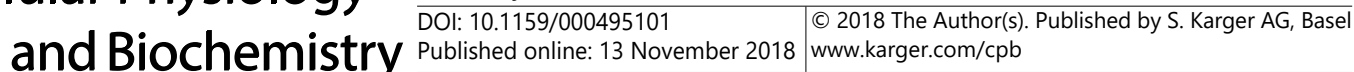 \\ Huang et al.: mRNAs and IncRNAs of Intramuscular Fat Related to Lipid Metabolism in \\ Pigs}

of MAPK cascade". In terms of molecular function, only "enzyme inhibitor activity" was a significantly enriched GO term. In the biological process category, the genes were mainly enriched in GO terms associated with extracellular matrix and axon. GO annotation suggested that the regulatory mechanism and regulatory genes of intramuscular fat deposition in LW and LY pigs might be significantly different and closely related to different genes.

\section{Pathway enrichment analysis of differentially expressed genes}

KEGG pathway enrichment analysis revealed that 143 genes were enriched in 94 signaling pathways, among which 31 signaling pathways were significantly enriched and involved 108 genes (Table S4). Specifically, many genes were significantly enriched in signaling pathways closely related to lipid metabolism and adipogenesis, including "MAPK signaling pathway", "PPAR signaling pathway", "Regulation of lipolysis in adipocytes", "Glycerophospholipid metabolism", "Insulin signaling pathway", etc. (Fig. 3). These results were consistent with the GO analysis results. MAPK and PPAR signaling pathways were the key pathways regulating adipocyte differentiation and lipid accumulation. A total of 14 genes and 9 genes were enriched in the above two pathways respectively, implying that these genes might play critical roles in regulating intramuscular adipogenesis and lipid metabolism in LW and LY pigs.

\section{Target genes of IncRNAs and functional analysis}

According to the correlation coefficient analysis, 462 differentially expressed mRNAs were found to co-express with differentially expressed lncRNAs (Table S5). LncRNA-mRNA co-expression network indicated that 26 IncRNAs which were at the central positions of the network with Degree (Degree Centrality) $\geq 30$ might play key roles in regulating intramuscular lipid accumulation (Table S6, Fig. 4). Cis-regulation analysis showed that few mRNAs was the target gene of differentially expressed lncRNAs (Table S7). Trans-regulation analysis showed that ten differentially expressed mRNAs related to lipid metabolism were trans-regulated by eight lncRNAs (Table S8, Table 2). According to the above three analyses, a total of 31 key lncRNAs were selected to investigate their functions in adipogenesis and lipid metabolism.

Fig. 3. KEGG pathway analysis of differentially expressed genes. Advanced bubble chart shows enrichment of differentially expressed genes in signaling pathways. Y-axis label represents pathway, and $\mathrm{X}$-axis label represents rich factor (rich factor = amount of differentially expressed genes enriched in the pathway/amount of all genes in background gene set). Size and color of the bubble represent amount of differentially expressed genes enriched in the pathway and enrichment significance, respectively. The figure was drawn using $\mathrm{R}$ language.

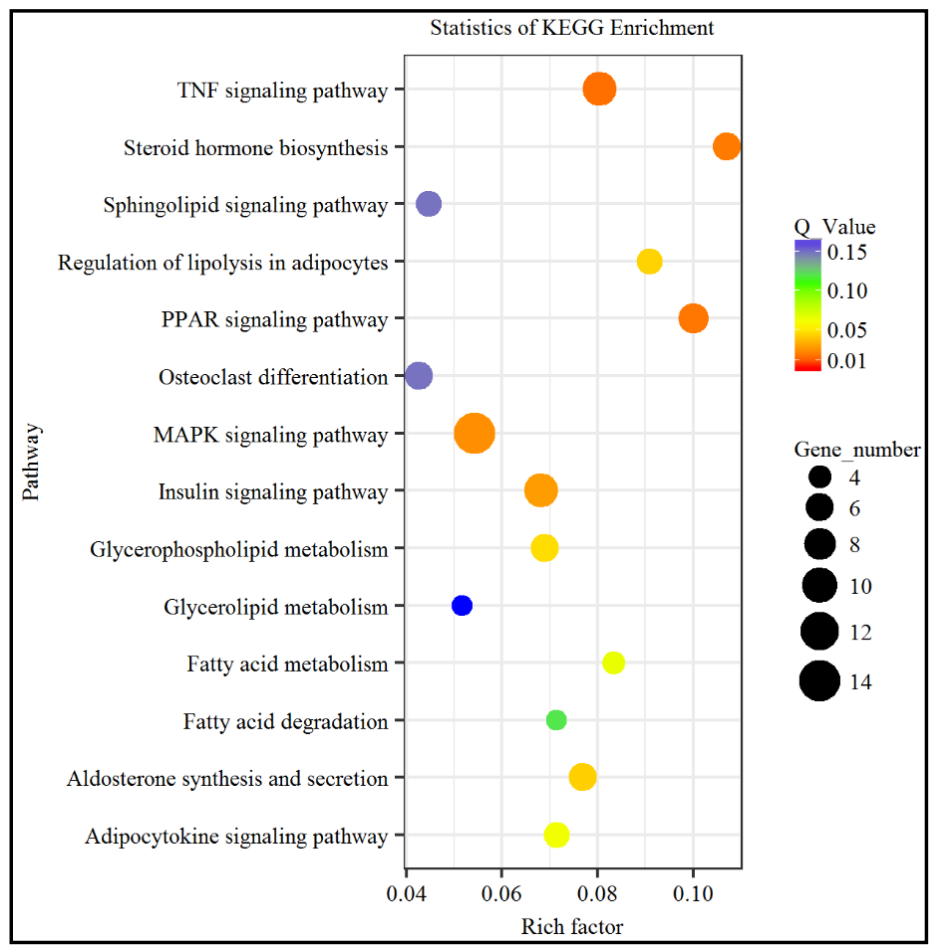


Fig. 4. Co-expression network of the differentially expressed IncRNAs and genes related to lipid metabolism. Note that color denotes differential expression levels. Red represents up-regulation and green represents d o wn - regulation. Size represents the importance of a node (Degree). The edge denotes the interaction strength. Circles and inverted triangles represent genes and IncRNAs, respectively. The figure was drawn using the software Cytoscape [43].

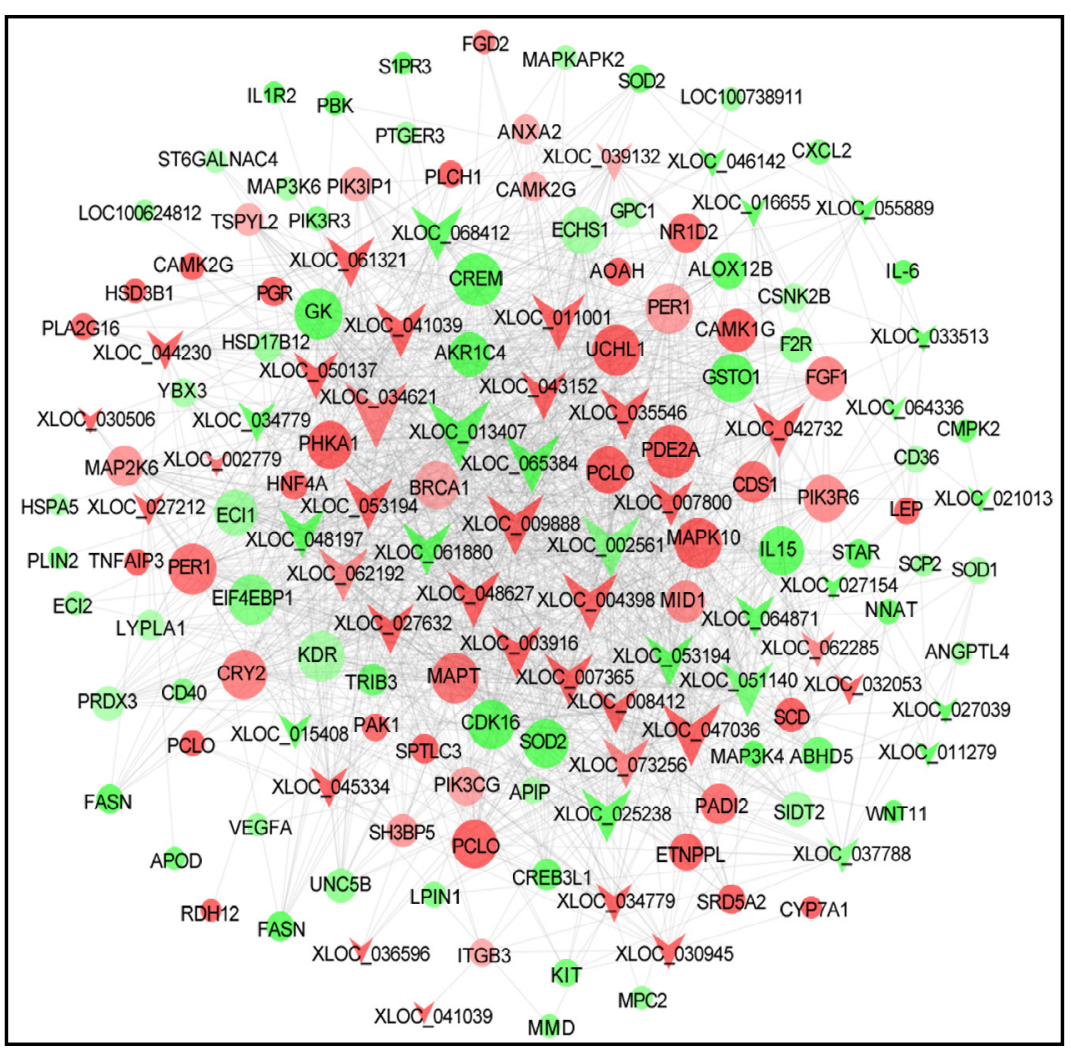

The target genes of IncRNAs were also significantly enriched in MAPK, PPAR signaling pathways and biological processes including lipid biosynthetic process, lipid metabolic process, fatty acid metabolism. This indicated that the differentially expressed lncRNAs might regulate adipogenic differentiation and lipid metabolism by targeting key genes involved in the above signaling pathways and biological processes. LncRNAs whose target genes were significantly enriched in MAPK and PPAR signaling pathways were selected for the construction of IncRNA-mRNA-signaling pathway network (Fig. 5). According to the network, the regulatory patterns of key lncRNAmRNA pairs were explored.

\section{qRT-PCR verification}

To validate the reliability of RNA-seq results, differentially expressed genes (five lncRNAs, six mRNAs) were randomly selected for further qRT-PCR verification (Table S9). qRT-PCR is considered as the golden standard for quantitative analysis of genes [49]. The results showed that FASN, TRIB3, MAPKAPK2, CD36, XLOC_046142, XLOC_053194 and XLOC_064871 were highly expressed in LY pig, while NR1D2, SCD, XLOC_027632 and XLOC_004938 were highly expressed in LW pig (Fig. 6). These data were consistent with the sequencing results, implying the reliability of the sequencing results. 


\section{Cellular Physiology Cell Physiol Biochem 2018;50:2406-2422

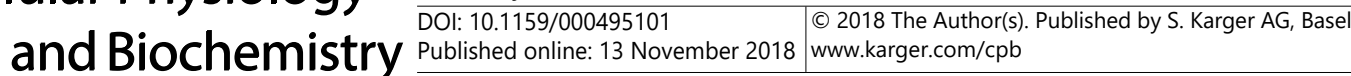 Huang et al.: mRNAs and IncRNAs of Intramuscular Fat Related to Lipid Metabolism in Pigs}

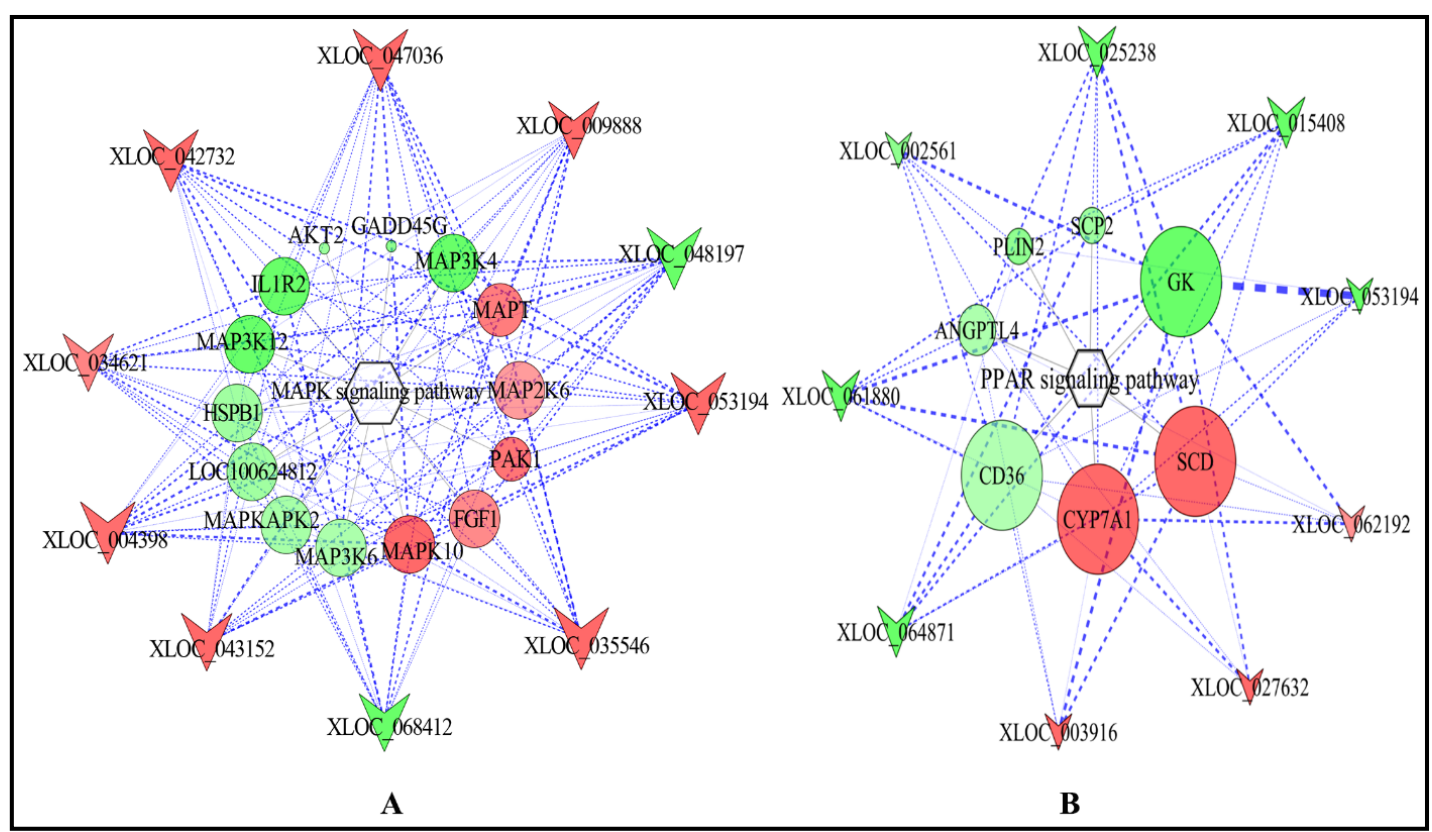

Fig. 5. The lncRNAs-genes-pathways network related to lipid metabolism. A. The MAPK signaling pathwaylncRNAs-genes network. B. The PPAR signaling pathway-lncRNA-genes network. Hexagons, circle notes and inverted triangles represent pathways, genes and lncRNAs, respectively. Color denotes differential expression levels. Red represents up-regulation, and green represents down-regulation. Size represents the importance of a node (Degree). The edge denotes the interaction strength. Both figures were drawn using the software Cytoscape [43].

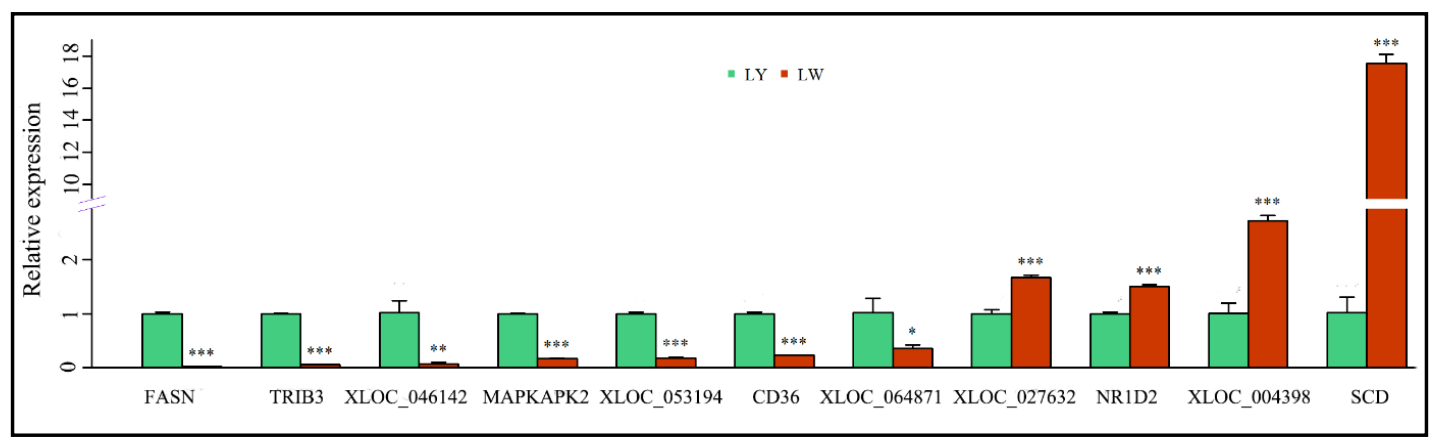

Fig. 6. qRT-PCR validation of the differentially expressed genes. The differential expression of genes in intramuscular fat between LY and LW pigs was validated by quantitative real-time PCR. * : P<0.05; ** : $\mathrm{P}<0.01 ;{ }^{* * *}: \mathrm{P}<0.001$. The figure was drawn using $\mathrm{R}$ language.

\section{Discussion}

Many researchers have used genome-wide RNA seq to study gene expression in pig intramuscular adipose tissue [50,51]. In light of their works, we compared the expression profile of genes and lncRNAs in intramuscular adipose tissue between LW and LY pigs by RNA-seq technology and comprehensively investigated intramuscular fat deposition and metabolism. KEGG enrichment analysis indicated that the differentially expressed genes in intramuscular adipose tissues between LW and LY pigs were mainly enriched in MAPK and PPAR signaling pathways. MAPK pathway, one of the important signal systems mediating cells' response to external stimuli, plays a key role in cell proliferation and differentiation. 


\section{Cellular Physiology Cell Physiol Biochem 2018;50:2406-2422

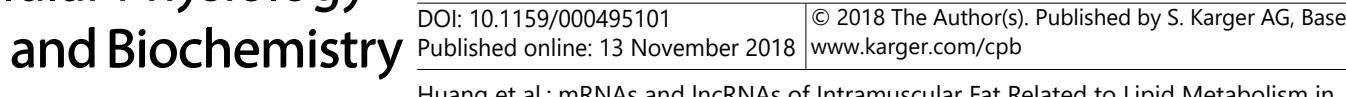 \\ Pigs}

In mammalian cells, there are four subgroups of MAPK: ERK1/2, JNK, p38 MAPK and ERK5/ BMK1, which are important for regulating adipocyte proliferation and differentiation [5254]. The precise understanding of the cascade of these molecular events and the way to regulate them will be crucial for efficiently treating obesity. PPAR signaling pathway is a key pathway closely associated with metabolism of fatty acid and sterols, and adipogenic differentiation [21, 55,56]. Lim et al. used qRT-PCR to analyze the genes associated with PPAR signaling pathway in the longissimus dorsi muscle of Hanwoo cattle [57].

In this study, AFGF/FGF1, AKT2, GADD45G, HSP27, IL1R2, LOC100624812, MAP2K6, MAP3K12, MAP3K4, MAP3K6, MAPK10, MAPKAPK2, MAPT and PAK1 were significantly enriched in MAPK signaling pathway. Except for AFGF and MAPT, which were associated with ERK1/2 signaling pathway, all other genes were associated with p38 MAPK signaling pathway. Aouadi et al [54]. comprehensively studied the role of p38 MAKP signaling pathway in regulating fat deposition in mice. They suggested that $\mathrm{p} 38$ MAPK could inhibit adipogenic differentiation by inhibiting the activity and expression of C/EBP $\beta$ and PPAR $\gamma$ during the whole process of lipogenesis in mice. The activity of p38 MAPK was remarkably low in the white adipose tissue of obese mice (ob/ob mice, high-fat diet, hereditary obesity) and preadipocytes separated from obese mice. In addition, other research showed that p38 MAPK signal could negatively regulate preadipocyte differentiation as well as subcutaneous and intramuscular fat deposition in broiler chicken [58-60], and inhibit lipogenesis in 3T3-L1 adipocyte [61]. However, p38 MAKP could promote the differentiation of human preadipocytes [62]. Taken together, the role of p38 MAPK in regulating adipocyte differentiation and lipid deposition might be related to species, cell type and developmental stage.

Note that these genes involved in $\mathrm{p} 38$ MAPK signaling pathway were mainly up-regulated in the intramuscular adipose tissue of LY pig in this study. This implied that p38 MAPK signaling pathway might be important for intramuscular fat deposition in pig, which was consistent with our previous study showing that MAPK signaling pathway may play a critical role in porcine adipogenesis [17]. Fat deposition is a complex process related to lipogenesis, adipocyte proliferation and differentiation. Previous research showed that the proliferation, differentiation and lipogenesis capability of preadipocytes was stronger in Bamei (fat-type) pig than in Landrace (lean-type) pig [13]. The intramuscular fat content in Erhualian pig (fattype) was remarkably different at different growth stages, whereas that in Large White pig changed little during growth [15]. Above research suggested that preadipocytes in obese pig breeds might have higher ability to proliferate and differentiate, thus more intramuscular fat was deposited in these pig breeds. This also implied that the intramuscular adipocytes in LY pig had weaker ability than those in LW pig to differentiate, proliferate and synthesize lipids. This might be a part of the reason that significantly less intramuscular fat was deposited in LY pig than in LW pig. On above basis, these genes enriched in p38 MAPK signaling pathway might mainly negatively regulate intramuscular adipogenic differentiation in LY pig and thus lead to deposition of less intramuscular fat. It was inferred that the 11 key lncRNAs such as XLOC_004398, XLOC_0053194, and XLOC_046142 could regulate the proliferation and differentiation of intramuscular adipocytes as well as lipogenesis in LW and LY pigs by target regulating these genes involved in p38 MAPK signaling pathway. The results were similar to those of Zhang et al., who found that the target genes of lncRNAs in abdominal fat tissue of chicken were significantly enriched in MAPK signaling pathway [18]. Note that XLOC_046142 might play a critical role in MAPK signaling pathway by trans-acting on MAPKAPK2.

In addition, the expression of $A F G F$ (FGF1) and MAPT genes were highly expressed in the intramuscular adipose tissue of LW pig. In humans, FGF1 is a kind of lipogenesis factor secreted by adipose microvascular endothelial cells [63] and can stimulate and induce the proliferation and differentiation of human preadipocytes through $F G F 1 / F G F R$ axis $[63,64]$. In mice, FGF1 can act as a key signal transduction protein to mediate the reconstruction of adipose tissue and regulate metabolic homeostasis through PPAR $\gamma$-FGF1 axis [65]. Therefore, FGF1 might potentially promote the proliferation and differentiation of intramuscular adipocytes in LW pig and play an important role in intramuscular fat deposition. 


\section{Cellular Physiology Cell Physiol Biochem 2018;50:2406-2422

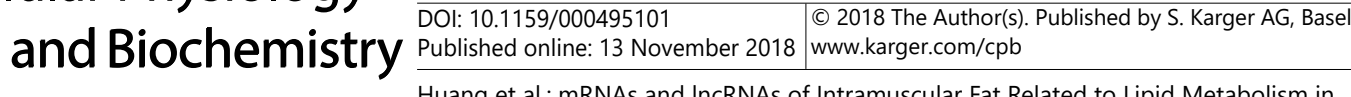 \\ Pigs}

In this study, SCP2, PLIN2, GK, CD36, ANGPTL4, SCD and CYP7A1 were significantly enriched in PPAR signaling pathway. Among them, SCD and CYP7A1 were highly expressed in $\mathrm{LW}$ pig.

SCD is the rate-limiting enzyme in the biosynthesis of unsaturated fatty acid. Besides, $S C D$ gene is a candidate key gene regulating intramuscular fat deposition $[8,9]$. It also plays an important role in regulating fatty acid metabolism and determining fatty acid composition in muscle $[66,67]$. In this study, $S C D$ was highly expressed in LW pig with high intramuscular fat content, which was consistent with current research. Compared with Duroc pig (lean type), LW pig has higher levels of intramuscular fat, saturated fatty acid (SFA) and monounsaturated fatty acid (MUFA) in its longissimus dorsi muscle [68]. Compared with Holstein cattle (low intramuscular fat level), Wagyu cattle (high intramuscular fat level) also has higher levels of MUFA in its intramuscular adipose tissue and longissimus dorsi muscle [69]. Since SFA and MUFA are key fatty acids determining meat quality, there should be significant difference in SAF and MUFA levels in adipose tissues between LW and LY pigs. The expression level of SCD is positively correlated with MUFA content [9], thus $S C D$ should promote MUFA biosynthesis and deposition in the intramuscular adipose tissue of LW pig. In this study, IncRNAs including XLOC_061880, XLOC_025238 (PCC<-0.94) and XLOC_003916 (PCC>0.94) ranked in the top three in terms of association with $S C D$ expression. This suggested that these lncRNAs might be important for $S C D$ expression. In sum, $S C D$ might play a key role in intramuscular fat deposition and fatty acid biosynthesis in LW pig. Seven key lncRNAs including XLOC_025238, XLOC_027632 and XLOC_062192 might promote the intramuscular fat deposition and MUFA synthesis in LW pig by regulating genes, especially $S C D$ gene, involved in PPAR signal pathway.

PLIN2 and FASN also play an important role in regulating intramuscular fat deposition $[69,11]$. PLIN2, an adipose differentiation-related protein (ADRP), is a kind of perilipin which can promote the biosynthesis and storage of fatty acid by coating lipid droplets [69]. In this study, PLIN2 was down-regulated in the intramuscular adipose tissue of LW pig. This was inconsistent with previous research showing that PLIN2 was highly expressed in in the longissimus dorsi muscles of LW pig in comparison with that of LY pig [12]. FASN is a key enzyme of de novo fatty acid synthesis and can catalyze malonyl-CoA to form fatty acid [70]. The expression level of FASN was high in the longissimus dorsi muscle of Berkshire pig with high intramuscular fat content during the slaughter period [11]. In this study, FASN was highly expressed in the RNA extracted from intramuscular adipose tissue of LY pig and the intramuscular adipose tissue was separated in the part of longissimus muscle, which was inconsistent with the result of above-mentioned study.

By trans-regulation analysis and network analysis of lncRNAs and differentially expressed genes associated with lipid metabolism, it was found that TRIB3, NR1D2, BRCA1 and AKR1C4 were trans-regulated by XLOC_064871, XLOC_004398, XLOC_011001 and XLOC_015408, respectively. TRIB3, a kind of pseudokinase, can inhibit the synthesis of fatty acid by binding E3 ubiquitin ligase and protect against diet-induced obesity by stimulating fatty acid oxidation in the adipose tissue of mice during fasting [71]. In addition, TRIB3 can negatively regulate the transcriptional activation of PPAR $\gamma$ and inhibit adipogenesis in 3T3L1 cells [72]. TRIB3 is expressed in porcine adipose tissue and skeletal muscle, and it is related to meat quality and production performance [73]. These indicate that TRIB3 might inhibit subcutaneous fat deposition in LY pig and be closely related to obesity-associated diseases. In this study, XLOC_064871 can trans-regulate TRIB3, indicating that XLOC_064871 might also play a vital role in adipocyte differentiation and fatty acid metabolism in pig. NR1D2 was highly expressed in skeletal muscle of Bantam chicken with high intramuscular fat content, and can induce the expression of PPARs, CEBP $\alpha$ and FABP4 genes, promoting adipogenic differentiation and affecting intramuscular fat deposition [74]. In this study, the expression of NR1D2 in intramuscular adipose tissue of LW pig was high, which was consistent with previous study. This indicated that NR1D2 might promote the adipogenic differentiation in pig and XLOC_004398 might play a role in intramuscular fat deposition in pig by interacting with NR1D2. GO annotation indicated that BRCA1 and AKR1C4 were mainly associated with fatty acid and lipid metabolism. Besides, previous study demonstrated that 


\section{Cellular Physiology Cell Physiol Biochem 2018;50:2406-2422 \begin{tabular}{ll|l} 
and Biochemistry Published online: 13 November 2018 & $\begin{array}{l}\text { ㄷ } 2018 \text { The Author(s). Published by S. Karger AG, Basel } \\
\text { www.karger.com/cpb }\end{array}$ \\
\hline
\end{tabular} \\ Huang et al.: mRNAs and IncRNAs of Intramuscular Fat Related to Lipid Metabolism in \\ Pigs}

highly expressed BRCA1 in the subcutaneous fat of obese people might help to control fatty acid biosynthesis in adipocytes and adipose tissue from obese subjects [75], which was in according with our study that BRCA1 was highly expressed in LW pig. This implied that $X L O C_{-} 011001$ might target BRCA1, playing a vital role in fatty acid and lipid metabolism as well as obesity controlling.

\section{Conclusion}

In this study, we applied RNA-seq technology and bioinformatics methods to identify differentially expressed lncRNAs and mRNAs of intramuscular adipose tissues between Laiwu and Large White pigs for exploring the molecular mechanisms of intramuscular fat deposition. Results indicated that 55 IncRNAs and 513 known mRNAs were differentially expressed. LncRNAs can target mRNAs involved in PPAR and MAPK signal transduction pathways and play an important in intramuscular fat accumulation and adipogenic differentiation. XLOC_046142, XLOC_064871, XLOC_004398, XLOC_011001, XLOC_025238 which might target MAPKAPK2, TRIB3, NR1D2, BRCA1, and SCD, respectively, play key regulatory roles. This study provides useful information for understanding molecular mechanism of intramuscular fat deposition in the studied pig breeds.

\section{Acknowledgements}

X.Y.M. conceived and designed the study and wrote the paper. W.L.H performed the experiment, analyzed data and wrote the paper. A.L.,X.X.Z. and L.L.X performed the experiment and interpreted the data. All the authors read and approved the final manuscript. This work was supported by a grant from the Agricultural Science and Technology Innovation Program (ASTIPIAS05), the National Basic Research and Development Program of China (973 Program) (No. 2015CB943100) and the Basic Research Fund for Central Public Research Institutes of CAAS (No. 2013ywf-zd-2).

\section{Disclosure Statement}

The authors declare that they have no competing interests.

\section{References}

1 Suzuki K, Irie M, Kadowaki H, Shibata T, Kumagai M, Nishida A: Genetic parameter estimates of meat quality traits in Duroc pigs selected for average daily gain, longissimus muscle area, backfat thickness, and intramuscular fat content. J Anim Sci 2005;83:2058-2065.

-2 Blachnio-Zabielska AU, Chacinska M, Vendelbo MH, Zabielski P: The Crucial Role of C18-Cer in Fat-Induced Skeletal Muscle Insulin Resistance. Cell Physiol Biochem 2016;40:1207-1220.

-3 Wang S, Zhou G, Shu G, Wang L, Zhu X, Gao P, Xi Q, Zhang Y, Yuan L, Jiang Q: Glucose utilization, lipid metabolism and BMP-Smad signaling pathway of porcine intramuscular preadipocytes compared with subcutaneous preadipocytes. Cell Physiol Biochem 2013;31:981-996.

4 Spurlock ME, Gabler NK: The development of porcine models of obesity and the metabolic syndrome. J Nutr 2008;138:397-402.

5 Koopmans SJ, Schuurman T: Considerations on pig models for appetite, metabolic syndrome and obese type 2 diabetes: From food intake to metabolic disease. Eur J Pharmacol 2015;759:231-239.

6 Shim J, Al-Mashhadi RH, Sorensen CB, Bentzon JF: Large animal models of atherosclerosis--new tools for persistent problems in cardiovascular medicine. J Pathol 2016;238:257-266. 


\section{Cellular Physiology Cell Physiol Biochem 2018;50:2406-2422 \begin{tabular}{l|l|l} 
and Biochemistry Published online: 13 November 2018 & $\begin{array}{l}\text { (c) } 2018 \text { The Author(s). Published by S. Karger AG, Basel } \\
\text { www.karger.com/cpb }\end{array}$ \\
\hline
\end{tabular} \\ Huang et al.: mRNAs and IncRNAs of Intramuscular Fat Related to Lipid Metabolism in Pigs}

7 Xing K, Zhu F, Zhai L, Chen S, Tan Z, Sun Y, Hou Z, Wang C: Identification of genes for controlling swine adipose deposition by integrating transcriptome, whole-genome resequencing, and quantitative trait loci data. Sci Rep 2016;6:23219.

-8 Zappaterra M, Deserti M, Mazza R, Braglia S, Zambonelli P, Davoli R: A gene and protein expression study on four porcine genes related to intramuscular fat deposition. Meat Sci 2016;121:27-32.

-9 Wang W, Xue W, Jin B, Zhang X, Ma F, Xu X: Candidate gene expression affects intramuscular fat content and fatty acid composition in pigs. J Appl Genet 2013;54:113-118.

10 Li WZ, Zhao SM, Huang Y, Yang MH, Pan HB, Zhang X, Ge CR, Gao SZ: Expression of lipogenic genes during porcine intramuscular preadipocyte differentiation. Res Vet Sci 2012;93:1190-1194.

11 Lim KS, Lee KT, Park JE, Chung WH, Jang GW, Choi BH, Hong KC, Kim TH: Identification of differentially expressed genes in longissimus muscle of pigs with high and low intramuscular fat content using RNA sequencing. Anim Genet 2017;48:166-174.

12 Cui J, Chen W, Liu J, Xu T, Zeng Y: Study on quantitative expression of PPARgamma and ADRP in muscle and its association with intramuscular fat deposition of pig. Springerplus 2016;5:1501.

13 Zhang GH, Lu JX, Chen Y, Zhao YQ, Guo PH, Yang JT, Zang RX: Comparison of the adipogenesis in intramuscular and subcutaneous adipocytes from Bamei and Landrace pigs. Biochem Cell Biol 2014;92:259-267.

14 Zhao J, Li K, Yang Q Du M, Liu X, Cao G: Enhanced adipogenesis in Mashen pigs compared with Large White pigs. Italian Journal of Animal Science 2017;16:217-225.

15 Gao QX, Li J, Liu HL, Wang LY, Xu YX: Comparative study on lipogenic and lipolytic gene expression in intramuscular fat tissue between growing Erhualian and large white pigs. Acta genetica Sinica 2004;31:1218-1225.

-16 Zhou ZY, Li A, Wang LG, Irwin DM, Liu YH, Xu D, Han XM, Wang L, Wu SF, Wang LX, Xie HB, Zhang YP: DNA methylation signatures of long intergenic noncoding RNAs in porcine adipose and muscle tissues. Sci Rep 2015;5:15435.

17 Huang WL, Zhang XX, Li A, Miao XY: Identification of differentially expressed genes between subcutaneous and intramuscular adipose tissue of Large White pig using RNA-seq. Hereditas 2017;39:501-511.

18 Zhang T, Zhang X, Han K, Zhang G, Wang J: Genome-Wide Analysis of IncRNA and mRNA Expression During Differentiation of Abdominal Preadipocytes in the Chicken. 2017;7:953-966.

19 Miao X, Luo Q, Qin X, Guo Y, Zhao H: Genome-wide mRNA-seq profiling reveals predominant downregulation of lipid metabolic processes in adipose tissues of Small Tail Han than Dorset sheep. Biochem Biophys Res Commun 2015;467:413-420.

20 Miao X, Luo Q Qin X, Guo Y: Genome-wide analysis of microRNAs identifies the lipid metabolism pathway to be a defining factor in adipose tissue from different sheep. Sci Rep 2015;5:18470.

21 Huang W, Guo Y, Du W, Zhang X, Li A, Miao X: Global transcriptome analysis identifies differentially expressed genes related to lipid metabolism in Wagyu and Holstein cattle. Sci Rep 2017;7:5278.

-22 Ramayo-Caldas Y, Mach N, Esteve-Codina A, Corominas J, Castello A, Ballester M, Estelle J, Ibanez-Escriche N, Fernandez AI, Perez-Enciso M, Folch JM: Liver transcriptome profile in pigs with extreme phenotypes of intramuscular fatty acid composition. BMC Genomics 2012;13:547.

-23 Zeng QY, Wang GL, Wei SD, Wang LY, Yang HL, Cao HF, Xu YH: Studies on carcass and meat quality performance of crossbred pigs with graded proportions of Laiwu Black genes. Hereditas 2005;27:65-69.

24 Qian Y, Zeng YQ Du JF, Cui JX, Li H, Chen QM, Song YP, Chen W: CDS cloning and relationship between intramuscular fat content and mRNA expression of PID1 gene in pig. Hereditas 2010;32:1153-1158.

25 Council NR: Nutrient Requirements of Swine: 10th Revised Edition, The National Academies Press, Washington, DC, 1998.

-26 Trapnell C, Pachter L, Salzberg SL: TopHat: discovering splice junctions with RNA-Seq. Bioinformatics 2009;25:1105-1111.

27 Kim D, Pertea G, Trapnell C, Pimentel H, Kelley R, Salzberg SL: TopHat2: accurate alignment of transcriptomes in the presence of insertions, deletions and gene fusions. Genome Biol 2013;14:R36.

-28 Trapnell C, Roberts A, Goff L, Pertea G, Kim D, Kelley DR, Pimentel H, Salzberg SL, Rinn JL, Pachter L: Differential gene and transcript expression analysis of RNA-seq experiments with TopHat and Cufflinks. Nat Protoc 2012;7:562-578. 


\section{Cellular Physiology Cell Physiol Biochem 2018;50:2406-2422 \begin{tabular}{l|l|l} 
and Biochemistry Published online: 13 November 2018 & $\begin{array}{l}\text { (c) } 2018 \text { The Author(s). Published by S. Karger AG, Basel } \\
\text { www.karger.com/cpb }\end{array}$ \\
\hline
\end{tabular} \\ Huang et al.: mRNAs and IncRNAs of Intramuscular Fat Related to Lipid Metabolism in \\ Pigs}

29 Trapnell C, Williams BA, Pertea G, Mortazavi A, Kwan G, van Baren MJ, Salzberg SL, Wold BJ, Pachter L: Transcript assembly and quantification by RNA-Seq reveals unannotated transcripts and isoform switching during cell differentiation. Nat Biotechnol 2010;28:511-515.

-30 Li H, Handsaker B, Wysoker A, Fennell T, Ruan J, Homer N, Marth G, Abecasis G, Durbin R, Genome Project Data Processing S: The Sequence Alignment/Map format and SAMtools. Bioinformatics 2009;25:20782079.

31 Koboldt DC, Chen K, Wylie T, Larson DE, McLellan MD, Mardis ER, Weinstock GM, Wilson RK, Ding L: VarScan: variant detection in massively parallel sequencing of individual and pooled samples. Bioinformatics 2009;25:2283-2285.

-32 Li A, Zhang J, Zhou Z: PLEK: a tool for predicting long non-coding RNAs and messenger RNAs based on an improved k-mer scheme. BMC Bioinformatics 2014;15:311.

-33 Sun L, Luo H, Bu D, Zhao G, Yu K, Zhang C, Liu Y, Chen R, Zhao Y: Utilizing sequence intrinsic composition to classify protein-coding and long non-coding transcripts. Nucleic Acids Res 2013;41:e166.

34 Kong L, Zhang Y, Ye ZQ Liu XQ, Zhao SQ, Wei L, Gao G: CPC: assess the protein-coding potential of transcripts using sequence features and support vector machine. Nucleic Acids Res 2007;35:W345-349.

35 Finn RD, Bateman A, Clements J, Coggill P, Eberhardt RY, Eddy SR, Heger A, Hetherington K, Holm L, Mistry J, Sonnhammer EL, Tate J, Punta M: Pfam: the protein families database. Nucleic Acids Res 2014;42:D222230.

-36 Li A, Zhang J, Zhou Z, Wang L, Liu Y, Liu Y: ALDB: a domestic-animal long noncoding RNA database. PLoS One 2015;10:e0124003.

-37 Anders S, Huber W: Differential expression analysis for sequence count data. Genome Biol 2010;11:R106.

38 Kanehisa M, Sato Y, Kawashima M, Furumichi M, Tanabe M: KEGG as a reference resource for gene and protein annotation. Nucleic Acids Res 2016;44:D457-462.

-39 Bindea G, Mlecnik B, Hackl H, Charoentong P, Tosolini M, Kirilovsky A, Fridman WH, Pages F, Trajanoski Z, Galon J: ClueGO: a Cytoscape plug-in to decipher functionally grouped gene ontology and pathway annotation networks. Bioinformatics 2009;25:1091-1093.

40 Tafer H, Amman F, Eggenhofer F, Stadler PF, Hofacker IL: Fast accessibility-based prediction of RNA-RNA interactions. Bioinformatics 2011;27:1934-1940.

41 Li Z, Ouyang H, Zheng M, Cai B, Han P, Abdalla BA, Nie Q, Zhang X: Integrated Analysis of Long Non-coding RNAs (LncRNAs) and mRNA Expression Profiles Reveals the Potential Role of LncRNAs in Skeletal Muscle Development of the Chicken. Front Physiol 2016;7:687.

42 Miao X, Luo Q Zhao H, Qin X: Co-expression analysis and identification of fecundity-related long noncoding RNAs in sheep ovaries. Sci Rep 2016;6:39398.

43 Smoot ME, Ono K, Ruscheinski J, Wang PL, Ideker T: Cytoscape 2.8: new features for data integration and network visualization. Bioinformatics 2011;27:431-432.

44 Chen Q Zeng Y, Wang H, Yang L, Yang Y, Zhu H, Shi Y, Chen W, Hu Y: Molecular characterization and expression analysis of NDUFS4 gene in m. longissimus dorsi of Laiwu pig (Sus scrofa). Mol Biol Rep 2013;40:1599-1608.

45 Shen Y, Mao H, Huang M, Chen L, Chen J, Cai Z, Wang Y, Xu N: Long Noncoding RNA and mRNA Expression Profiles in the Thyroid Gland of Two Phenotypically Extreme Pig Breeds Using Ribo-Zero RNA Sequencing. Genes (Basel) 2016;7:

46 Ran M, Chen B, Li Z, Wu M, Liu X, He C, Zhang S, Li Z: Systematic Identification of Long Noncoding RNAs in Immature and Mature Porcine Testes. Biol Reprod 2016;94:77.

47 Wang F, Li L, Xu H, Liu Y, Yang C, Cowley AW, Jr., Wang N, Liu P, Liang M: Characteristics of long non-coding RNAs in the Brown Norway rat and alterations in the Dahl salt-sensitive rat. Sci Rep 2014;4:7146.

48 Cabili MN, Trapnell C, Goff L, Koziol M, Tazon-Vega B, Regev A, Rinn JL: Integrative annotation of human large intergenic noncoding RNAs reveals global properties and specific subclasses. Genes Dev 2011;25:1915-1927.

49 Risso D, Ngai J, Speed TP, Dudoit S: Normalization of RNA-seq data using factor analysis of control genes or samples. Nat Biotechnol 2014;32:896-902.

50 Sodhi SS, Park WC, Ghosh M, Kim JN, Sharma N, Shin KY, Cho IC, Ryu YC, Oh SJ, Kim SH, Song KD, Hong SP, Cho SA, Kim HB, Jeong DK: Comparative transcriptomic analysis to identify differentially expressed genes in fat tissue of adult Berkshire and Jeju Native Pig using RNA-seq. Mol Biol Rep 2014;41:6305-6315. 


\section{Cellular Physiology Cell Physiol Biochem 2018;50:2406-2422 \begin{tabular}{l|l|l} 
and Biochemistry & $\overline{\text { DOl: 10.1159/000495101 }}$ & $\begin{array}{l}\text { C) } 2018 \text { The Author(s). Published by S. Karger AG, Basel } \\
\text { www.karger.com/cpb }\end{array}$ \\
\hline
\end{tabular}}

Huang et al.: mRNAs and IncRNAs of Intramuscular Fat Related to Lipid Metabolism in Pigs

51 Corominas J, Ramayo-Caldas Y, Puig-Oliveras A, Estelle J, Castello A, Alves E, Pena RN, Ballester M, Folch JM: Analysis of porcine adipose tissue transcriptome reveals differences in de novo fatty acid synthesis in pigs with divergent muscle fatty acid composition. BMC Genomics 2013;14:843.

52 Bost F, Aouadi M, Caron L, Binetruy B: The role of MAPKs in adipocyte differentiation and obesity. Biochimie 2005;87:51-56.

53 Bost F, Aouadi M, Caron L, Even P, Belmonte N, Prot M, Dani C, Hofman P, Pages G, Pouyssegur J, Le Marchand-Brustel Y, Binetruy B: The extracellular signal-regulated kinase isoform ERK1 is specifically required for in vitro and in vivo adipogenesis. Diabetes 2005;54:402-411.

-54 Aouadi M, Laurent K, Prot M, Le Marchand-Brustel Y, Binetruy B, Bost F: Inhibition of p38MAPK increases adipogenesis from embryonic to adult stages. Diabetes 2006;55:281-289.

55 Farmer SR: Regulation of PPARgamma activity during adipogenesis. Int J Obes (Lond) 2005;29 Suppl 1:S13-16.

56 Li A, Huang W, Zhang X, Xie L, Miao X: Identification and Characterization of CircRNAs of Two Pig Breeds as a New Biomarker in Metabolism-Related Diseases. Cell Physiol Biochem 2018;47:2458-2470.

57 Lim D, Chai HH, Lee SH, Cho YM, Choi JW, Kim NK: Gene Expression Patterns Associated with Peroxisome Proliferator-activated Receptor (PPAR) Signaling in the Longissimus dorsi of Hanwoo (Korean Cattle). Asian-Australas J Anim Sci 2015;28:1075-1083.

58 Yan J, Gan L, Chen D, Sun C: Adiponectin impairs chicken preadipocytes differentiation through p38 MAPK/ ATF-2 and TOR/p70 S6 kinase pathways. PLoS One 2013;8:e77716.

-59 Jun Y, Xiao T, Guoyong Y, Min F, Haili Y, Chao S: Recombinant globular adiponectin inhibits lipid deposition by p38 MAPK/ATF-2 and TOR/p70 S6 kinase pathways in chicken adipocytes. Biochem Cell Biol 2014;92:53-60.

60 Yan J, Gan L, Qi R, Sun C: Adiponectin decreases lipids deposition by p38 MAPK/ATF2 signaling pathway in muscle of broilers. Mol Biol Rep 2013;40:7017-7025.

-61 Feng M, Tian L, Gan L, Liu Z, Sun C: Mark4 promotes adipogenesis and triggers apoptosis in 3t3-11 adipocytes by activating jnk1 and inhibiting p38mapk pathways. Biology of the cell 2014;106:294-307.

62 Aouadi M, Jager J, Laurent K, Gonzalez T, Cormont M, Binetruy B, Le Marchand-Brustel Y, Tanti JF, Bost F: p38MAP Kinase activity is required for human primary adipocyte differentiation. FEBS Lett 2007;581:5591-5596.

63 Hutley L, Shurety W, Newell F, McGeary R, Pelton N, Grant J, Herington A, Cameron D, Whitehead J, Prins J: Fibroblast growth factor 1: a key regulator of human adipogenesis. Diabetes 2004;53:3097-3106.

64 Widberg CH, Newell FS, Bachmann AW, Ramnoruth SN, Spelta MC, Whitehead JP, Hutley LJ, Prins JB: Fibroblast growth factor receptor 1 is a key regulator of early adipogenic events in human preadipocytes. Am J Physiol Endocrinol Metab 2009;296:E121-131.

65 Jonker JW, Suh JM, Atkins AR, Ahmadian M, Li P, Whyte J, He M, Juguilon H, Yin YQ, Phillips CT, Yu RT, Olefsky JM, Henry RR, Downes M, Evans RM: A PPARgamma-FGF1 axis is required for adaptive adipose remodelling and metabolic homeostasis. Nature 2012;485:391-394.

66 Yu K, Shu G, Yuan F, Zhu X, Gao P, Wang S, Wang L, Xi Q, Zhang S, Zhang Y, Li Y, Wu T, Yuan L, Jiang Q: Fatty acid and transcriptome profiling of longissimus dorsi muscles between pig breeds differing in meat quality. Int J Biol Sci 2013;9:108-118.

-67 Ros-Freixedes R, Gol S, Pena RN, Tor M, Ibanez-Escriche N, Dekkers JC, Estany J: Genome-Wide Association Study Singles Out SCD and LEPR as the Two Main Loci Influencing Intramuscular Fat Content and Fatty Acid Composition in Duroc Pigs. PLoS One 2016;11:e0152496.

$68 \mathrm{Hu} \mathrm{H}$, Wang J, Guo J, Zhang H, Shen Y, W Y: Correlation of H-FABP gene expression with IMF and fatty acid content in Laiwu pigs and Duroc. Acta Agric Boreali Sin. 2010; 25: 64-68.

69 Shirouchi B, Albrecht E, Nuernberg G, Maak S, Olavanh S, Nakamura Y, Sato M, Gotoh T, Nuernberg K: Fatty acid profiles and adipogenic gene expression of various fat depots in Japanese Black and Holstein steers. Meat Sci 2014;96:157-164.

70 Smith S, Witkowski A, Joshi AK: Structural and functional organization of the animal fatty acid synthase. Prog Lipid Res 2003;42:289-317.

71 Qi L, Heredia JE, Altarejos JY, Screaton R, Goebel N, Niessen S, Macleod IX, Liew CW, Kulkarni RN, Bain J, Newgard C, Nelson M, Evans RM, Yates J, Montminy M: TRB3 links the E3 ubiquitin ligase COP1 to lipid metabolism. Science 2006;312:1763-1766. 


\section{Cellular Physiology Cell Physiol Biochem 2018;50:2406-2422}

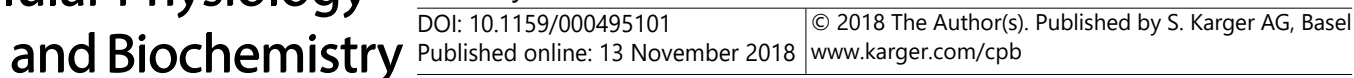

Huang et al.: mRNAs and IncRNAs of Intramuscular Fat Related to Lipid Metabolism in Pigs

72 Takahashi Y, Ohoka N, Hayashi H, Sato R: TRB3 suppresses adipocyte differentiation by negatively regulating PPARgamma transcriptional activity. J Lipid Res 2008;49:880-892.

73 Fontanesi L, Colombo M, Scotti E, Buttazzoni L, Bertolini F, Dall'Olio S, Davoli R, Russo V: The porcine tribbles homolog 3 (TRIB3) gene: Identification of a missense mutation and association analysis with meat quality and production traits in Italian heavy pigs. Meat Sci 2010;86:808-813.

74 Ye Y, Lin S, Mu H, Tang X, Ou Y, Chen J, Ma Y, Li Y: Analysis of differentially expressed genes and signaling pathways related to intramuscular fat deposition in skeletal muscle of sex-linked dwarf chickens. Biomed Res Int 2014;2014:724274.

-75 Ortega FJ, Moreno-Navarrete JM, Mayas D, Garcia-Santos E, Gomez-Serrano M, Rodriguez-Hermosa JI, Ruiz B, Ricart W, Tinahones FJ, Fruhbeck G, Peral B, Fernandez-Real JM: Breast cancer 1 (BrCa1) may be behind decreased lipogenesis in adipose tissue from obese subjects. PLoS One 2012;7:e33233. 